\title{
STUDY ON ECOLOGICAL AND ENVIRONMENTAL SUITABILITY OF TOURISM RESOURCES DEVELOPMENT IN LIJIANG RIVER BASIN OF GUILIN, CHINA
}

\author{
Ning $\mathrm{Li}^{1,2,3}$, Jinye Wang ${ }^{2}$, Haoyu Wang ${ }^{2,3, *}$, Xianli Yang ${ }^{1, *}$ \\ ${ }^{1}$ Bowen College of Management Guilin University of Technology, Guilin 541006, China \\ ${ }^{2}$ Guilin University of Technology, Guiling 541006, China \\ ${ }^{3}$ Key Laboratory of spatial information and mapping of Guangxi, Guilin 541006, China
}

KEY WORDS:RS/GIS; Ecologically sensitive areas; Ecological and environmental suitability; Lijiang River Basin

\begin{abstract}
:
Ecology and environmental suitability are widely used in urban ecology and regional ecology. However, there is still a lack of systematic evaluation method system for the research impacts of tourism development and tourism resource development on ecology and environment in ecologically sensitive scenic spots. Taking Lijiang River Basin, an ecologically sensitive area with typical karst landforms, as an example, this paper analyses the ecological and environmental suitability of tourism development from the perspective of space. In this paper, TM image and DEM model were firstly used to extract NDVI, slope, slope aspect and other related data. Then, based on the characteristics of the study area, the data of each factor was graded and assigned with a grade value, and the spatial situation of each single factor was analyzed, and superposition was carried out at last. Meanwhile, the study area is divided into three levels for tourism development, namely, unsuitable area, sub-suitable area and suitable area.
\end{abstract}

\section{Introduction}

Ecology and natural environment are the foundation of regional tourism resources exploitation. There is an interaction between the development of tourism resources and the ecological environment. On the one hand, it shows the impact of tourism development on the ecology and environment, including positive and negative effects. On the other hand, it also shows the restriction of ecology and natural environment on tourism exploitation and development (Jia et al., 2006)). At present, the ecological environment and social problems caused by over-exploitation of tourism have gradually emerged, thus maintaining the integrity and health of the ecosystem in tourist areas has become a new requirement of tourism exploitation (Feng, Jia, 2009).

From 1980 s to 1990 s, scholars at home and abroad have studied the relationship between tourism and environment (Wang,1986; Song, et al.,1985; EDWARDS,1987; HERCOCK,1999). Currently, the impact of tourism resources development on the environment is mainly evaluated by traditional methods. There is few studies on the relationship between tourism resources development and environment by using big data and combining modern technology, especially the lack of ecological and environmental suitability of tourism resource development from the perspective of spatial latitude. Based on the technology of Geographic Information Systems (GIS) and Remote Sensing (RS), this paper studies the ecological and environmental suitability of tourism resources development in Lijiang River Basin, which is ecologically sensitive region, using NDVI, slope and slope aspect as three ecological sensitive factors. From the perspective of spatial latitude, the ecological environment suitability of tourism resource development is quantitatively evaluated by combining multiple ecological sensitive factors, which is of great reference significance to regional tourism resource development and environmental protection.

\section{Study area and data source}

\subsection{Study area}

The Lijiang River Basin is located in the northern Latitude $24^{\circ} 38^{\prime} 10^{\prime \prime}-25^{\circ} 53^{\prime} 59^{\prime \prime}$, east longitude $110^{\circ}$ $07^{\prime} 39^{\prime \prime}$ - $110^{\circ} 42^{\prime}$ 57", which include Xiangshan District, Xiufeng District, Qixing District, Diecai District, Yanshan District as well as partial region of Xingan County, Lingchuan County, Lingui County, Yangshuo County, Pingle County in Guilin. Maoershan, the source of Lijiang River, is a national nature reserve. Guilin Lijiang Scenic Area, a world natural heritage site, is located in the Lijiang River Basin. Lijiang Scenic Area is the largest and most beautiful karst scenic spot in the world.

\subsection{Data source}

DEM data with resolution of $30 \mathrm{~m}$ were downloaded from geospatial data cloud (http://www.gscloud.cn/). Slope and aspect of the data were analyzed using ArcGIS 10 software. 2000 Landsat 5 TM data with path 124 and 125 and row 42 and 43 and less than $10 \%$ cloud was downloaded from the US Geological Survey (USGS). 


\section{Methods}

\subsection{Selection of ecological factors and weight assignment}

Three sensitive factors, NDVI, slope and aspect, were analyzed. The analytic hierarchy process (AHP) combined with statistical method was used to evaluate the whole research area on the basis of the above three factors superimposed by GIS platform. The grade assignment of each factor was shown in Table 1.

Table 1. Assignment of each eco-sensitive factors

\begin{tabular}{|c|c|c|c|}
\hline $\begin{array}{c}\text { Degree } \\
\text { assignment }\end{array}$ & Slope $\left(^{\circ}\right)$ & Aspect $\left(^{\circ}\right)$ & NDVI \\
\hline 1 & $46-90$ & $0-72$ & NDVI $\leq 0$ \\
2 & $36-45$ & $73-144$ & $0<\mathrm{NDVI} \leq 0.21$ \\
3 & $26-35$ & $145-216$ & $0.21<\mathrm{NDVI} \leq 0.5$ \\
4 & $6-25$ & $217-288$ & $0.50<\mathrm{NDVI} \leq 0.72$ \\
5 & $0-5$ & $289-360$ & $0.72<\mathrm{NDVI} \leq 1$ \\
\hline
\end{tabular}

\subsection{Data processing and thematic mapping}

The main contents of single factor evaluation and ecological mapping in the study area include three ecological sensitive factors: slope, aspect and NDVI index, among which the data processing and ecological mapping methods of slope and aspect factors are mainly based on the original DEM data of the study area and the analysis of slope and aspect information with the help of ArcGIS software, and the ecological mapping is completed. NDVI index factor is first calculated by Band Math after radiation calibration, atmospheric correction, mosaic and clipping with ENVI 5.3 based on TM image data of the study area, and then the results are transferred to ArcGIS platform to further complete the corresponding ecological mapping. The extraction process of each factor is shown in figure 1. Finally, the relevant data are extracted and superimposed to analyze the impact of tourism resources development on the ecological and natural environment.

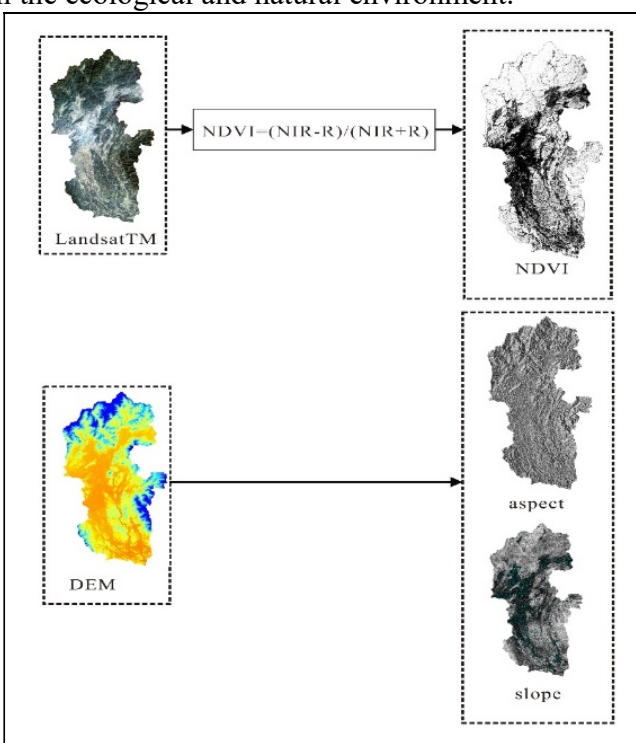

Figure 1. Extraction process diagram of each factor

\section{Results}

\subsection{Slope analysis}

Slope analysis is mainly used to describe the steepness of the terrain in the study area, which reflects the of landscape effect in close range. The bigger the slope is, the more likely the landscape will be seen and noticed. However, from the perspective of ecological environmental bearing capacity, the bigger the slope is, the worse the bearing capacity is, and minor ecotourism activities may cause greater ecological damage. In such a region, the impact of human activities on the landscape will be greater. The bigger it is. Slope with less than $5^{\circ}$ is gentle land, the ecological bearing capacity is relatively large. According to the slope grading system of the National Geographic Federation Geomorphological Survey and Geomorphological Cartography Commission(Feng, et al.,), combined with the geological and geomorphological characteristics of the Lijiang River Basin, the gradient of the study area is divided into flat slope $\left(0-5^{\circ}\right)$, gentle slope $\left(6-25^{\circ}\right)$, steep slope $\left(26-35^{\circ}\right)$, steep slope $\left(36-45^{\circ}\right.$, ) dangerous slope $\left(46-90^{\circ}\right)$. The slope proportions are shown in Figure 2. The results show that most areas of Lijiang River Basin have smaller slopes, gentle terrain fluctuations, flat slopes and gentle slopes account for more than $80 \%$ of the total, but in terms of a single factor of slope, they are more suitable for tourism development activities.

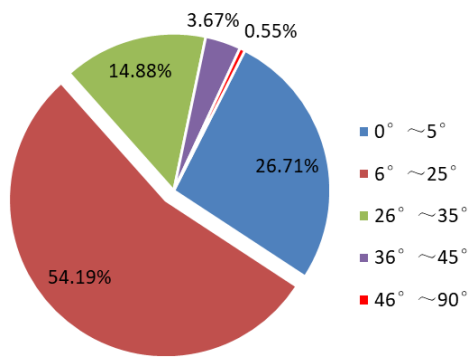

Figure 2. Percentage of slope in Lijiang River Basin

\subsection{Aspect analysis}

Aspect analysis mainly reflects the complexity of micro-topography in the study area. Generally speaking, the sunny slope (southeast slope) is not conducive to plant growth because of its high solar radiation intensity, rapid evaporation of soil moisture, and the decrease of soil moisture content in dry period; the shady slope (northwest slope) is more water and fertilizer-conserving than the sunny slope, which is conducive to plant growth. The advantages of the east west slope lie between the sunny and shady slopes. Aspect analysis can reflect the landscape effect in close range. The vegetation landscape on shady slope is generally better to resist the influence of human activities, while sunny slope is opposite. According to the DEM model, this study divides 5 directions of $0^{\circ}$ $\sim 72^{\circ}, 73^{\circ} \sim 144^{\circ}, 145^{\circ} \sim 216^{\circ}, 217^{\circ} \sim 288^{\circ}$ and $289^{\circ}$ $\sim 360^{\circ}$ for aspect statistics, the proportion of each direction is shown in the figure 3 . From the analysis results, the proportion of all directions is basically identical. 


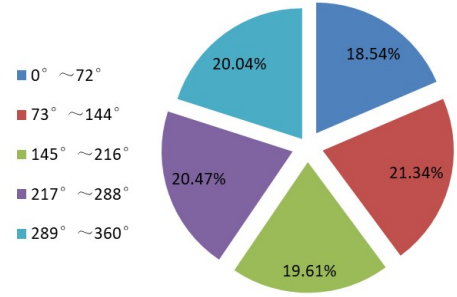

Figure 3. Percentage of aspect in Lijiang River Basin

\subsection{NDVI analysis}

The vegetation condition in scenic spots is an important basis for the existence of various tourism resources. Through its ecological effect, green plants can purify the air and improve the local climate, as well as give benign feedback to the ecological and natural environment, which plays a vital role in maintaining the ecological system balance of scenic spots. Vegetation index is a simple and effective empirical measure of surface vegetation status. It is a quantitative value of surface vegetation status extracted from multi-spectral remote sensing data, which can reflect the growth status and distribution characteristics of vegetation. Previous studies have shown that the normalized difference vegetation index (NDVI) is an important indicator for long-term ecological and environmental monitoring in ecologically sensitive areas, which is mainly suitable for describing regional landscape with sparse vegetation coverage and wide difference in coverage. According to the research, when the NDVI value is between -1 and 1 , the values with different ranges represent different vegetation regional distribution (Table 2) (Ding, Tasifulati, 2002). The proportion of NDVI distribution in Lijiang River Basin is shown in the figure 4, among which $\mathrm{NDVI} \leq 0$ accounts for $38.21 \%$ and $\mathrm{NDVI} \leq 0.50$ accounts for $57.95 \%$, indicating that at least half of the vegetation distribution in Lijiang River Basin is sparse and the coverage rate is low. It is not suitable to concentrate on high-intensity tourism activities.

Table 2 The qualitative description of NDVI

\begin{tabular}{|c|l|}
\hline Vegetation Index & \multicolumn{1}{|c|}{ Vegetation distribution } \\
\hline NDVI $\leq 0$ & $\begin{array}{l}\text { Unvegetated areas such as } \\
\text { deserts, gobi, waters and } \\
\text { residential areas }\end{array}$ \\
\hline $0<\mathrm{NDVI} \leq 0.21$ & $\begin{array}{l}\text { Areas with sparse vegetation and } \\
\text { low growth activity }\end{array}$ \\
\hline \multirow{3}{*}{$0.21<\mathrm{NDVI} \leq 0.50$} & $\begin{array}{l}\text { There are sporadic vegetation, } \\
\text { and there are sporadic vegetation } \\
\text { distribution around traffic and } \\
\text { construction land }\end{array}$ \\
\hline $0.50<\mathrm{NDVI} \leq 0.72$ & $\begin{array}{l}\text { Areas of cultivated land, } \\
\text { vegetable plots and roads around } \\
\text { villages and towns surrounded by } \\
\text { a few trees }\end{array}$ \\
\hline $0.72<\mathrm{NDVI} \leq 1$ & $\begin{array}{l}\text { A densely vegetated forest belt, } \\
\text { consisting mainly of natural or } \\
\text { planted forest belts, arable land, } \\
\text { and vegetable fields with large } \\
\text { areas of distribution }\end{array}$ \\
\hline
\end{tabular}

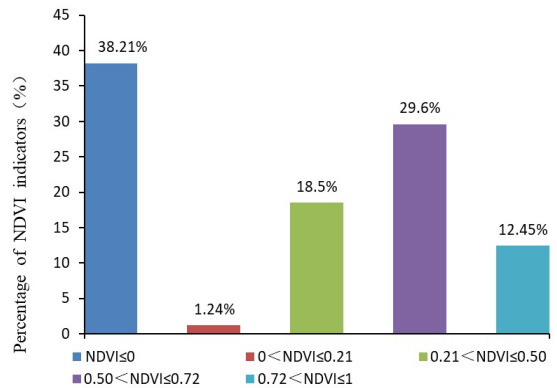

Figure 4. Proportion of NDVI indicators in Lijiang River Basin

\subsection{Analysis of ecological environment suitability}

According to the calculation results of each single factor, we divide the tourism resources into different levels, then give the corresponding scores for each level, and give the corresponding weights for each attribute. Then we make a superposition analysis to generate the spatial ecological and environmental suitability distribution map of tourism resources development (Figure 5). From the figure, we can see the spatial distribution characteristics of ecological and environmental suitability in Lijiang River Basin: most areas have low ecological and environmental suitability, and the eco-suitable areas for tourism development are mainly located in areas with relatively low elevation, small slope and relatively high vegetation coverage.

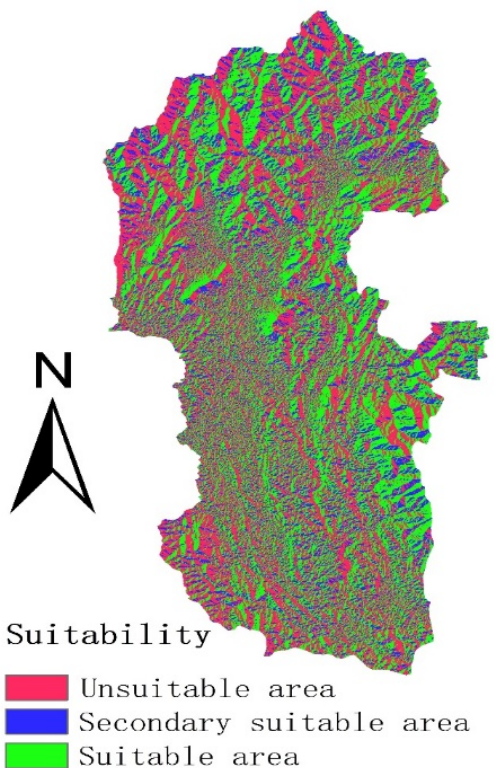

Figure 5. The suitability of ecology and environment about the development of tourism resources in Lijiang River Basin

\section{Conclusions and discussion}

(1) The development of ecotourism in typical karst landform areas is of great significance, but relevant theories are not perfect. Especially in the fragile ecological environment, how to develop eco-tourism and minimize the impact on the environment is still very weak. 
(2) With the continuous development of GIS technology and remote sensing technology, the application of GIS technology and remote sensing technology to quantitative analysis and evaluation of tourism environment quality is an effective means and method of tourism environment evaluation research, and it is also the future development trend. However, the application of GIS technology and remote sensing technology in tourism environmental assessment is still in its infancy.

(3) In this paper, GIS related software and remote sensing technology are used to quantitatively evaluate the impact of ecological environment on the spatial distribution of tourism development in Lijiang River Basin. The research results are highly targeted and operable for the study area, and provide a certain basis for the development, planning and construction of regional tourism resources. However, it is only a tentative study on the eco-environmental suitability evaluation of tourism development in the spatial dimension, and further exploration is needed on the reasonable selection of influencing factors, the accuracy of data extraction and the determination of factor weight.

\section{Acknowledgements}

This paper is financially supported by Guangxi education department youth teacher basic ability improvement project under grant number 2017KY1360, Guangxi Key Laboratory of Spatial Information and Geomatics Program (Contract Nos. 151400734, 163802518 and 163802531).

\section{References}

Ding, J. L., Tasifulati, T. Y. B. Research on the change of vegetation ecological landscape pattern in Oasis Based on NDVI [J]. Geography and Geo-information Science, 2002, 18 (1): 23-26.

EDWARDS J R. The UK heritage coasts : An assessment of the ecological impacts of tourism[J]. Annals of Tourism Research, 1987, 14(1): 71-87.

Feng, Y. F., Jia, T. F. Eco-security-oriented model of tourism development and Its Empirical Study --Taking tourism development of Salawusu River Basin in Inner Mongolia as an example [J]. Journal of Arid Land Resources and Environment, 2009, 23 (6): 181-186.

Feng, J. M., Guo L. X., Chen, L. X. Research on topographic characteristics of land use change and ecological effects in Shenmu County in recent 10 years $[\mathrm{J}]$. Research of Soil and Water Conservation, 2016, 23 (3): 132-136

HERCOCK M. The impacts of recreation and tourism in the remote North Kimberly region of Western Australia[J]. Environmentalist, 1999, 19(3): 259-275.

Jia, T. F., Zhang, Z. G., Jia, T. F., et al. Research on the ecological and environmental suitability of tourism resources development in ecologically sensitive areas: Taking Dongsheng District of Ordos City, Inner Mongolia as an example [J]. Resources Science, 2006,
28(5): 134-139.

Song, L. F., Yang, G. X., Guo, L. X. Evolution of tourism environment in Beijing-Tianjin area [J]. Acta Scientiae Circumstantiae, 1985, 5(3): 255-265.

Wang, J. X. The value of Landscape Tourism in Suzhou and the Countermeasures of environmental protection [J]. Environmental Science, 1986, (4): $85-105$ 